\title{
Analyzing Energy Consumption for Factory and Logistics Planning Processes
}

\author{
Egon Müller, Hendrik Hopf, and Manuela Krones \\ Department of Factory Planning and Factory Management \\ Institute of Industrial Sciences and Factory Systems \\ Chemnitz University of Technology \\ Chemnitz, Germany \\ \{egon.mueller, hendrik.hopf, manuela.krones\} amb.tu-chemnitz.de
}

\begin{abstract}
Energy efficiency increasingly becomes a relevant objective in industry. Factory planning plays an important role for energy-efficient factory, production and logistics systems. The design of systems and processes in intralogistics, as an essential part of factory planning, is in the focus of this paper. Existing approaches for energy efficiency-oriented planning of logistics systems are either empirical or theoretical. The paper describes an approach combining both aspects. With the presented approach, the energy consumption of a system in a factory can be determined and evaluated systematically. As a result, energy efficiency measures are deduced and generalized. The approach provides energy data and knowledge to support analyzing and optimization activities in planning processes.
\end{abstract}

Keywords: Energy Efficiency, Analysis of Energy Consumption, Factory Planning, Logistics Planning.

\section{Introduction}

Energy efficiency becomes a more and more important objective for industrial companies due to several factors, e.g. rising energy prices, growing environmental awareness and energy policy conditions. The EU member states agreed on the principle of “20/20/20 by $2020 "$, i.e. a $20 \%$ reduction in greenhouse gases, a $20 \%$ share of renewable energies and a $20 \%$ increase in energy efficiency by the year 2020 compared to 1990 [1]. The national implementation differs between the countries. For example, Germany wants to take a pioneering role and therefore adopted the "Energy Concept 2050", which staggers the achievement of goals in different phases. The greenhouse gas emissions should be reduced by $40 \%$ until 2020, by $55 \%$ until 2030 and by at least $80 \%$ until 2050 [2].

Industrial companies have recognized this trend and implement corporate strategies for improving sustainability and energy efficiency. The energy efficiency of the entire factory system does not result directly from the sum of individual parts or actions, i.e. individual actions can affect each other positively or negatively. Only through a holistic view of the complex coherences and interactions of individual resources, processes 
and structures of a factory, energy optimization potentials of the overall process or the total system can be exploited [3].

Therefore, factory planning plays a significant role for energy efficiency of factory, production and logistics systems. Despite of this importance, there is still a demand on tools and methods to integrate energy efficiency in planning processes systematically.

In the Cluster of Excellence eniPROD ${ }^{\circledR}$, which is a collaboration of Chemnitz University of Technology and Fraunhofer Institute for Machine Tools and Forming Technology, the research is focused on "Energy-Efficient Product and Process Innovations in Production Engineering". An objective of eniPROD ${ }^{\circledR}$ is a national and international visible contribution to realizing the vision of an almost emission-free production while simultaneously reducing the demand for energy as well as increasing the efficiency of resources [4]. One of the specific issues is "Energy-Efficient Systems and Processes in Logistics and Factory Planning".

The contribution of logistics to energy efficiency is often neglected by practitioners. But it is estimated that $40 \%$ of the energy consumption in production are caused by production surroundings which have their greatest share in logistics processes [5]. Especially in the field of intralogistics, there are only few scientific publications to support energy efficiency-oriented planning [6]. The presented approach for analysis and evaluation of energy consumption has been developed within eniPROD ${ }^{\circledR}$ to meet these deficits.

The remainder of the paper is organized as follows: In section 2, the basics of energy efficiency in logistics systems are presented. Section 3 contains the developed approach, which is applied to a use case in section 4. A short discussion and an outlook on further research are given in section 5 .

\section{Energy Efficiency in Logistics Systems}

Energy efficiency, in general, is defined by the ratio of useful process output and energy input [7]. Possibilities to reduce energy consumption are either technological (e.g. reducing friction) or organizational (e.g. reducing transport effort or switching off components when they are currently not used). Technological measures often lead to a change of construction and cause additional costs. Organizational measures can often be realized without additional costs.

Scientific problems in the field of energy efficiency are highly diversified. A main problem to raise energy efficiency consists in the understanding and modeling of the relationship between energy consumption and its causes. Methods that have been developed for this problem are mostly found in the field of machine tools and can be divided into empirical and theoretical approaches (figure 1). Empirical methods focus on the collection and comparison of energy data for different states of operating. Afterwards, these data can be used for simulation studies [8], [9]. Theoretical approaches use models to describe the influence of different variables on energy consumption [10], [11]. 
A transfer of the fore-mentioned methods to logistics systems is hardly possible, because their structure and functions are very heterogeneous (e.g. transport, storage, picking and packaging). There are only few scientific publications considering systematic approaches to increase energy efficiency in logistics systems. For instance, an empirical approach is presented by Prasse et al. [12]. A theoretical analysis on energy efficiency improvement based on a physical model is performed by Zhang et al. [13], but there is no verification of the theoretical findings with empirical studies.

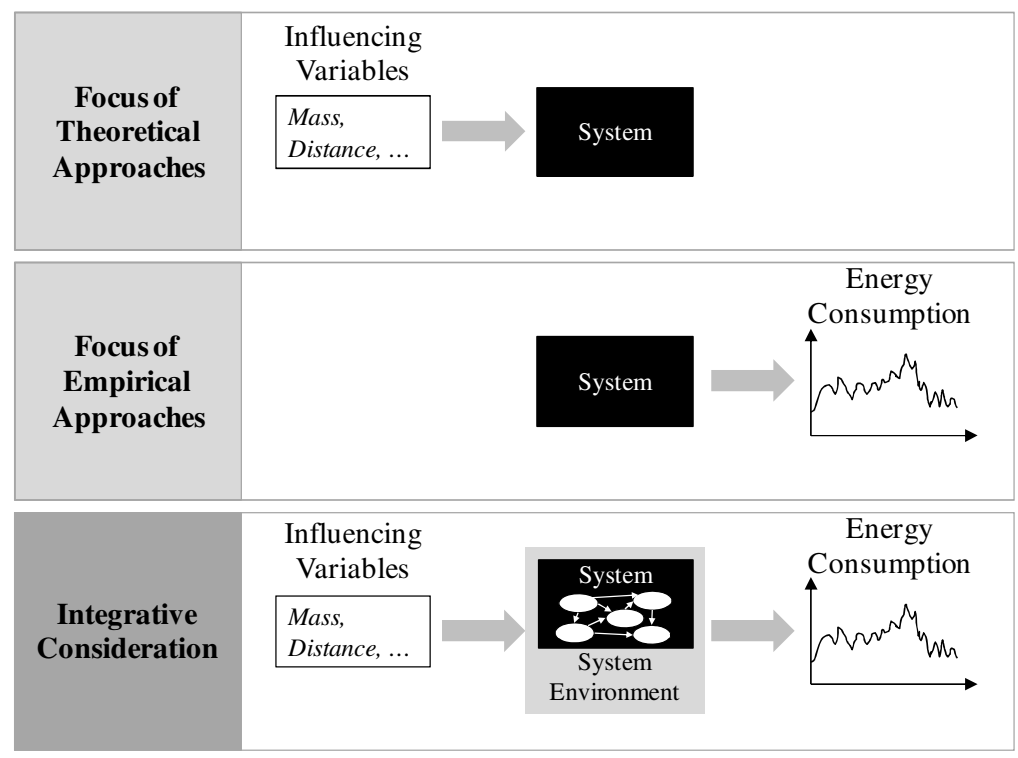

Fig. 1. Comparison between different approaches to analyze the energy consumption

\section{Approach for Analysis and Evaluation of Energy Consumption}

The presented approach uses an integrative consideration of theoretical and empirical methods (figure 1). The goal is to determine and evaluate the energy consumption of a system and to deduce energy efficiency measures based on this. The approach is divided into seven steps (figure 2).

In the first step, "Definition of Target Figures", the considered system is chosen as object of investigation and the goal of the analysis as well as the target figures are defined. A typical goal of the analysis is to determine the energy consumption depending on different operating states of the system. In this case, electrical power and electrical work can be defined as target figures. In the further procedure, possible influencing variables need to be identified and evaluated regarding their quantitative effect.

Then, the system is described in detail and available data is collected in the step "Definition of System Boundaries \& Data Acquisition". The analyzed system is 
separated into subsystems, elements, structures and processes to define the system boundaries. Different description models can be used for this task (e.g. hierarchical or peripheral order). A system is gradually divided into subsystems with the hierarchical order. The peripheral order structures a system according to the dependence on the master production schedule [14]. Thus, the energy consumption can be traced to its origin. After that, required information about energy carriers, processes or materials etc. is gathered. If the system is similar to other systems, the results of the analysis could be transferred in order to reduce effort.

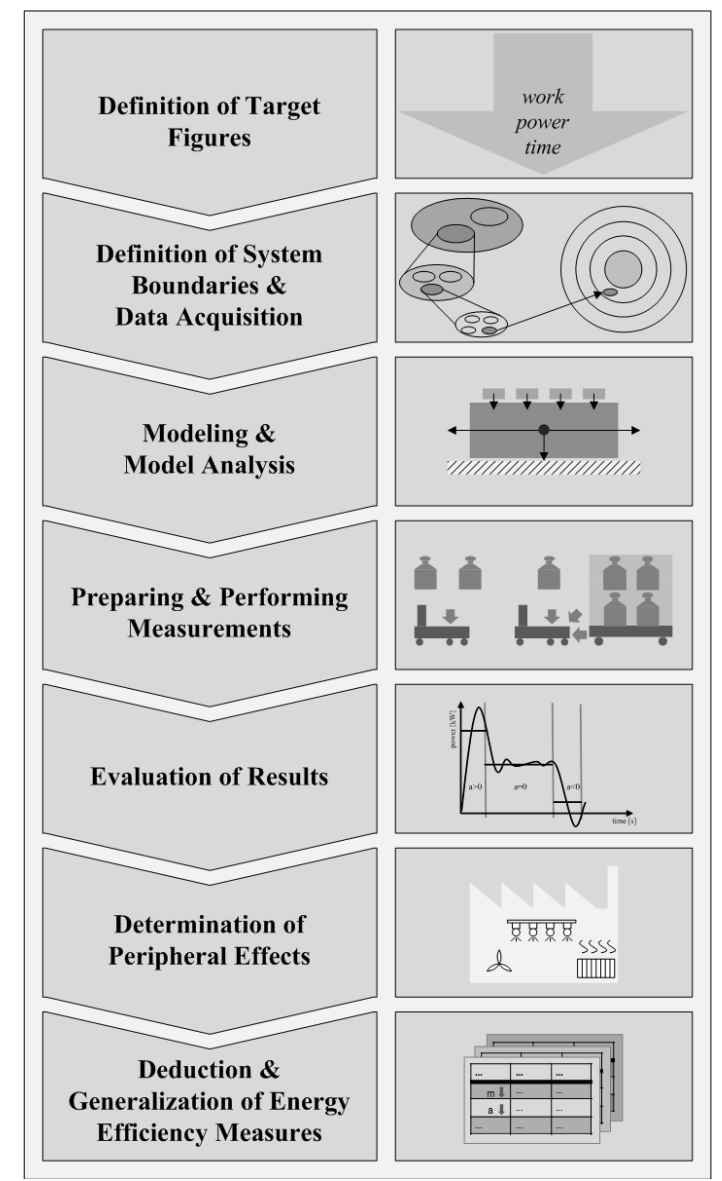

Fig. 2. Approach for analysis and evaluation of energy consumption

A central step is the "Modeling \& Model Analysis", which comprises creating a model of the system and identifying influencing variables on energy efficiency. Physical principles in the model describe how the defined target figures (see step 1) depend on the influencing variables. According to the system boundaries (see step 2), the influencing variables are divided into control and disturbance variables. Control variables can be changed within the system boundaries, whereas disturbance variables 
cannot be influenced. After modeling, the effects of changing control variables are analyzed. Two advantages can be achieved with this theoretical consideration: Firstly, the effects of energy efficiency measures can be estimated without affecting the real system in its operation. Secondly, the operating states can be specified for the preparation of the practical examination.

In the next step, "Preparing \& Performing Measurements", the energy consumption of the system is measured in order to test the theoretical findings practically. The measuring variables, points and instruments are defined on the basis of the target figures and influencing variables (see step 3). Possible measuring points are the main connection (e.g. control cabinet) or the connections of the components (e.g. drive motors). Batteries or their charging stations can be used as measuring points for material handling vehicles. Measuring instruments can be stationary or mobile. Special attention should be paid to the acquisition of process data in addition to energy data in order to link this data.

Theoretical and practical results are compared in the step "Evaluation of Results". The measured values can be summarized with the use of statistical metrics according to the required accuracy. Key figures, e.g. specific energy consumption, are calculated to compare different planning or operation alternatives. Depending on the system complexity, visualization in form of energy flow charts or diagrams is helpful for better understanding.

The sixth step, "Determination of Peripheral Effects", is very important for energy efficiency-oriented factory and logistics planning. The energy consumption depends on the design and operation of a system. Energy measurements often focus just on this direct consumption. But in addition, indirect energy consumption is caused by the area taken up within a superior system (e.g. energy demand for HVAC and lighting). Intralogistics systems, e.g. transport systems, typically take up a great share of the floor space, so the indirect energy consumption should not be disregarded.

The last step consists of the "Deduction and Generalization of Energy Efficiency Measures". Based on the findings of theoretical and practical analysis, influencing variables and optimization opportunities are pointed out. Recommendations for energy efficiency-oriented planning and energy-efficient operation of the system are generalized.

\section{Use Case "Automated Guided Vehicle"}

The application of the approach is presented on an example in the "Experimental and Digital Factory" of the Department of Factory Planning and Factory Management [15]. Further practical case studies were performed in an industrial environment [16]. The automated guided vehicle "MOVE" of Trilogiq was selected to analyze electrical power and electrical energy consumption depending on the transport task (figure 3). The investigation focuses on the vehicle operation, not on the construction. Therefore, it is not further separated into its components (e.g. drive, control system), although this would be possible for analyzing the dependence between the energy consumption and the vehicle's construction. The points for material transfer and battery charging stations belong to the system environment. 
The only needed energy form is electrical power, which is provided by two lead batteries with each $12 \mathrm{~V}$ voltage and 120 Ah capacity. The vehicle uses magnetic navigation with a passive guide line and passive ground markers to follow a programmed route.

The physical model is build in order to deduce the influencing variables on energy consumption. It bases on the planar motion of a particle. The energy consumption of electrical components is not considered at this point. The mechanical work is calculated as target figure by adding the forces due to rolling and acceleration resistance. The influencing variables are divided into control and disturbance variables. As only the vehicle operation is analyzed, the control variables are the mass of the transported goods, the number of acceleration processes, the distance and the velocity. A sensitivity analysis is used to order the variables according to their predicted influence. The ratio between energy consumption and transport effort (specific energy consumption) is calculated as key figure.

Afterwards, the practical measurement was performed by absolving a driving cycle with different transport loads and different velocities. The insights of the analysis of the physical model were tested. The energy consumption was recorded by the battery controller "WI-iQ ${ }^{\circledR}$ " from EnerSys/Hawker, which transfers the data of the current power consumption to a laptop by wireless communication. It is important to log the position of the vehicle and its driving time in order to connect energy and process data, i.e. to assign the energy consumption to different parts of the driving cycle.
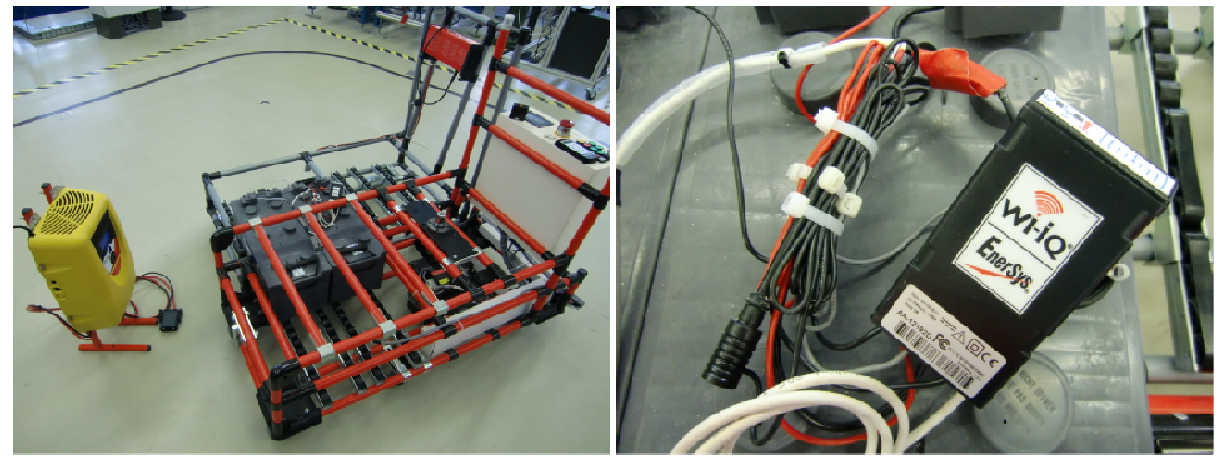

Fig. 3. Analyzed automated guided vehicle (left) and battery controller (right)

When the measured results were evaluated, there were, at first, differences between the model and the real energy consumption. This means, the mechanical energy used for the movement, which is calculated with the physical model, represents only a part of the consumed electrical energy. However, the important influencing variables were identified before the measurements. As one measured result, less acceleration processes led to reduced energy consumption. Whereas, the reduction of velocity led to a reverse effect: Although the electrical power was reduced, the time for the driving cycle increased and therefore, energy consumption increased, too. The specific energy consumption was calculated again from the measured values. Increasing transport 
load led to the decrease of the specific energy consumption i.e. makes the transport more efficient. In general, this depends on the relation between the mass of the transported goods and the mass of the vehicle.

After performing the measurements, the peripheral effects were analyzed. The automated guided vehicle needs area for transportation as well as for loading and unloading (about $28 \%$ of the floor space), so indirect energy consumption is caused. Additionally, the battery charging stations need air-conditioning. If the energy consumption of the vehicle is reduced, the battery needs to be charged less often and therefore, the charging components could be smaller sized.

In the last step, energy efficiency measures are generalized. As already mentioned, transport distance has a great influence on energy consumption and should therefore be reduced. If the transport route cannot be modified, distance can be reduced by summarizing transports, which leads to increasing transport loads. The effect of aggregating two transports was analyzed with the physical model as well as with another measurement and led to $30 \%$ energy savings.

\section{Conclusions}

It was shown that energy efficiency becomes more and more important for industrial systems and processes. Hence, there is a demand on energy efficiency-oriented tools and methods.

A systematic approach for analysis and evaluation of energy consumption was presented and exemplarily applied. The approach describes the collection and the interpretation of energy data in order to analyze energy consumption of logistics systems. Based on this, energy efficiency measures are deduced and generalized. The approach was demonstrated on the example of an automated guided vehicle. The structured procedure helped to predict the effects of energy efficiency measures and moreover, to prepare and perform measurements systematically and with less effort.

The measured values can be applied for process modeling and simulation. Different planning or operation alternatives can be compared regarding their energy efficiency. Besides the scientific application, industrial companies are able to realize energy-efficient processes with the help of this approach.

Acknowledgements. The Cluster of Excellence "Energy-Efficient Product and Process Innovation in Production Engineering" (eniPROD ${ }^{\circledR}$ ) is funded by the European Union (European Regional Development Fund) and the Free State of Saxony.
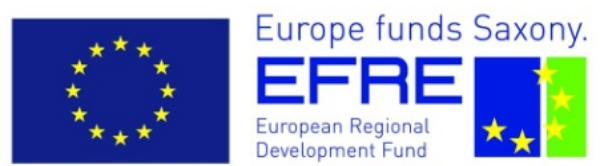

European Union 


\section{References}

1. Council of the European Union, http://register.consilium.europa.eu/ pdf/en/07/st07/st07224-re01.en07.pdf

2. Federal Ministry of Economics and Technology: Energy Concept for an Environmentally Sound, Reliable and Affordable Energy Supply, http: / / www. bmu. de/files / english/pdf/application/pdf/energiekonzept_bundesregierung_ en.pdf

3. Müller, E., Löffler, T.: Energy Efficiency at Manufacturing Plants - A Planning Approach. In: 43rd CIRP International Conference on Manufacturing Systems, Vienna, pp. 787-794 (2010)

4. Neugebauer, R.: Energy-Efficient Product and Process Innovation in Production Engineering - 1st International Colloquium of the Cluster of Excellence eniPROD. Wissenschaftliche Scripten, Chemnitz (2010)

5. Hellingrath, B., Schürrer, S.: Software in der Logistik - Klimaschutz im Fokus. In: ten Hompel, M. (ed.) Energieeffizienz und Umweltbilanz von Supply Chains, pp. 16-21. Huss, Munich (2009)

6. Schmidt, T., Schulze, F.: Simulationsbasierte Entwicklung energieeffizienter Steuerungsstrategien für Materialflusssysteme. In: Vojdani, N. (ed.) 7th Colloquium of the Scientific Association for Technical Logistics (WGTL), pp. 150-159. Praxiswissen Service, Dortmund (2011)

7. Müller, E., Engelmann, J., Löffler, T., Strauch, J.: Energieeffiziente Fabriken planen und betreiben. Springer, Heidelberg (2009)

8. Herrmann, C., Thiede, S.: Process Chain Simulation to Foster Energy Efficiency in Manufacturing. CIRP J. Manuf. Sci. Technol. 1, 221-229 (2009)

9. Larek, R., Brinksmeier, E., Meyer, D., Pawletta, T., Hagendorf, O.: A Discrete-Event Simulation Approach to Predict Power Consumption in Machining Processes. Prod. Engineer. 5, 575-579 (2011)

10. Dietmair, A., Verl, A., Eberspaecher, P.: Model-Based Energy Consumption Optimization in Manufacturing System and Machine Control. Int. J. Manuf. Res. 6, 380-401 (2011)

11. Seow, Y., Rahimifard, S.: A Framework for Modeling Energy Consumption within Manufacturing Systems. CIRP J. Manuf. Sci. Technol. 4, 258-264 (2011)

12. Prasse, C., Kamagaew, A., Gruber, S., Kalischewski, K., Soter, S., ten Hompel, M.: Survey on Energy Efficiency Measurements in Heterogeneous Facility Logistics Systems. In: IEEE International Conference on Industrial Engineering and Engineering Management, Singapore, pp. 1140-1144 (2011)

13. Zhang, S., Xia, X.: Modeling and Energy Efficiency Optimization of Belt Conveyors. Appl. Energ. 88, 3061-3071 (2011)

14. Schenk, M., Wirth, S., Müller, E.: Factory Planning Manual - Situation-Driven Production Facility Planning. Springer, Heidelberg (2009)

15. Horbach, S., Ackermann, J., Müller, E., Schütze, J.: Building Blocks for Adaptable Factory Systems. Robot. Cim.-Int. Manuf. 27, 735-740 (2011)

16. Veit, T., Fischer, S., Strauch, J., Krause, A.: Umsetzung logistischer Strategien unter Berücksichtigung der Energieeffizienz. In: Müller, E., Spanner-Ulmer, B. (eds.) Tagungsband 4. Symposium Wissenschaft und Praxis \& 8. Fachtagung Vernetzt Planen und Produzieren - VPP 2010, pp. 167-181. Wissenschaftliche Schriftenreihe des IBF, Chemnitz (2010) 